\title{
Testosterone suppresses oxidative stress via androgen receptor-independent pathway in murine cardiomyocytes
}

\author{
LI ZHANG ${ }^{1}$, SAIZHU WU $^{1}$, YUNJUN RUAN ${ }^{2}$, LEI HONG $^{1}$, XIAOWEN XING $^{3}$ and WENYAN LAI ${ }^{4}$ \\ ${ }^{1}$ Department of Cardiology, Nangfang Hospital, Southern Medical University, Guangzhou 510515; \\ ${ }^{2}$ Department of Cardiology, Guangzhou General Hospital of Guangzhou Military Area Command of Chinese PLA, \\ Guangzhou 510010; ${ }^{3}$ Laboratory of Cardiovascular Diseases, The First Affiliated Hospital of Guangzhou \\ Medical College, Guangzhou 510120; ${ }^{4}$ Laboratory of Cardiovascular Diseases, Nanfang Hospital, \\ Southern Medical University, Guangzhou, Guangdong 510515, P.R. China
}

Received April 12, 2011; Accepted July 18, 2011

DOI: $10.3892 / \mathrm{mmr} .2011 .539$

\begin{abstract}
Evidence supports that oxidative stress exerts significant effects on the pathogenesis of heart dysfunction. On the other hand, the presence of specific androgen receptor (AR) in mammalian cardiomyocytes implies that androgen plays a physiological role in cardiac function, myocardial injury and the regulation of the redox state in the heart. This study used the testicular feminized (Tfm) and castrated male mice to investigate the effects of testosterone deficiency, physiological testosterone therapy and AR on oxidative stress in cardiomyocytes. Tfm mice have a non-functional AR and reduced circulating testosterone levels. Male littermates and Tfm mice were separated into 5 experimental groups: non-castrated littermate controls, castrated littermates, sham-operated Tfm, testosterone-treated castrated littermates and testosteronetreated sham-operated Tfm mice. Cardiomyocytes that were isolated from the left ventricle were used for determination of superoxide dismutase (SOD), glutathione peroxidase (GSH-Px) enzyme activities, and malondialdehyde (MDA) levels. Additionally, mitochondrial DNA (mtDNA) deletion mutations were detected by nested PCR. The SOD and GSH-Px enzyme activities of cardiomyocytes were decreased, and the MDA levels and the proportion of mtDNA mutations were increased in castrated and sham-operated Tfm mice compared to control mice. However, an increase was observed in the activities of SOD and GSH-Px enzyme as well as a decrease in MDA levels and the proportion of mtDNA mutations in the mice that had received testosterone therapy. These changes were statistically similar in castrated and sham-operated Tfm
\end{abstract}

Correspondence to: Dr Saizhu Wu, Department of Cardiology, Nanfang Hospital, Southern Medical University, Guangzhou, Guangdong 510515, P.R. China

E-mail:wusaizhu@126.com

Key words: cardiomyocyte, testosterone, oxidative stress, androgen receptor, castration mice after testosterone therapy. In conclusion, it is testosterone deficiency that induces oxidative stress in cardiomyocytes. Physiological testosterone therapy is able to suppress oxidative stress mediated via the AR-independent pathway.

\section{Introduction}

Testosterone is the major male androgen and deficiencies in circulating levels are a prominent feature observed in aging males. Testosterone exerts a variety of anabolic and androgenic effects on many organs, most of which are mediated by the nuclear androgen receptor (AR). The AR is expressed in mammalian and primate cardiomyocytes, suggesting that androgens may play a role in normal heart function $(1,2)$. Low testosterone levels or androgen deficiency have been found to increase cardiovascular risk factors and produce adverse effects on cardiac function $(2,3)$. Furthermore, testosterone therapy in humans (4) and rats (5) with low testosterone levels has been shown to improve cardiac function.

Substantial evidence supports the view that oxidative stress may exert effects on the pathogenesis of heart dysfunction (6). Cardiomyocytes are rich in mitochondria that can provide rapid and substantial ATP production to meet increased energy demands for increased work. However, this increased energy production can lead to an increased reactive oxygen species (ROS) generation that can surmount antioxidant defenses and lead to the intrinsic generation of oxidative stress (7). Low concentrations of ROS are necessary to the normal function of cellular activities and can regulate enzyme activity, signal transcription, and gene expression. However, at high concentrations they may damage cellular components, including DNA, RNA, proteins and lipids (8). Not only are mitochondria the major source of ROS, but they are also immediate targets of the pathological insult. Oxidative damage to mitochondrial DNA (mtDNA) by ROS may induce nucleotide and mtDNA mutations. Accumulation of mutations and oxidative damage to mtDNA may result in increased ROS in mitochondria and induction of further mtDNA mutations $(9,10)$.

Bekesi et al reported that testosterone treatment decreases superoxide anion production in human neutrophils, suggesting 
a possible antioxidant effect (11). In contrast, testosterone may directly induce oxidative stress in mammalian tissues (12). Little is known of the effects of testosterone on the regulation of oxidative stress in the heart. This experimental design allowed us to assess the effect of testosterone deficiency and physiological testosterone therapy on the activities of superoxide dismutase (SOD) and glutathione peroxidase (GSH-Px) enzyme, levels of oxidative damage in lipids quantified by malondialdehydes (MDAs), and the proportion of mtDNA deletion mutations in murine cardiomyocytes. Other studies have demonstrated that testosterone modulates the production of ROS in cerebellar granule cells via an AR mediated mechanism (13). Hence, we assessed whether the effects of testosterone on the above-mentioned changes were mediated via AR-dependent pathways.

\section{Materials and methods}

Experimental animals and design. All experimental procedures were approved by the Animal Research Committee of Nanfang Hospital, Southern Medical University. Breeder mice were purchased from the Model Animal Research Center of

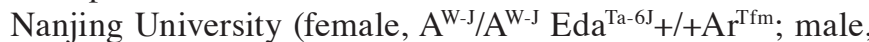

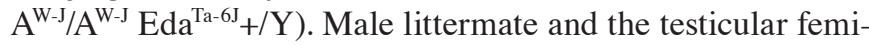
nized (Tfm) mice were bred in our laboratory. The gender of the Tfm mice was determined by PCR. Tfm mice exhibit an $\mathrm{X}$-linked, single-base-pair deletion in the gene encoding the AR. This deletion results in premature termination of AR protein synthesis, which in turn leads to a non-functional AR $(14,15)$. In addition, circulating levels of testosterone are reduced in the Tfm mouse, reportedly 10-fold lower compared to its male littermate (15).

At 8 weeks of age, male littermate and Tfm mice underwent either surgical castration or sham operation, respectively. Four weeks following operation, castrated mice were treated with $(n=8)$ or without $(n=8)$ testosterone propionate (Guangzhou Mingxing Pharmaceutical Co.; 070701), while sham-operated Tfm mice were also treated with $(n=8)$ or without $(n=7)$ testosterone propionate. Testosterone was injected intramuscularly at $3 \mathrm{mg} / \mathrm{kg}$ body weight, diluted in sesame oil, once every $72 \mathrm{~h}$ for 3 months. Age-matched 24-week-old non-surgical littermates were used as the control $(n=8)$. Pharmacokinetic determination of physiological testosterone was conducted before these manipulations.

Pharmacokinetic determination of physiological testosterone therapy. To establish and maintain a dosing regimen of testosterone to physiological concentrations, we first had to determine the appropriate volume and frequency of $25 \mathrm{mg} / \mathrm{ml}$ testosterone propionate. At 8 weeks of age, male littermate mice $(n=36)$ underwent surgical castration and were then allowed to recover in individual cages for 4 weeks. Consequently, 12-week-old mice received a single $3 \mathrm{mg} / \mathrm{kg}$ intramuscular injection of testosterone propionate (the human replacement dose of testosterone propionate is $0.35 \mathrm{mg} / \mathrm{kg}$ administered 2-3 times per week). Mice were sacrificed in serial intervals at $30 \mathrm{~min}$ and at 1, 2, 4, 8, 16, 24, 32, 48 and $72 \mathrm{~h}$ after injection, and testosterone concentrations were measured. To ensure reproducibility, 18 additional castrated littermates received a second-cycle injection (double administration) beginning at
$72 \mathrm{~h}$ after the first and were sacrificed at 1, 2, 4, 8, 24 and $72 \mathrm{~h}$ after the second injection. At the same time, in order to determine normal testosterone concentrations, 9 non-castrated male mice were sacrificed at 00:00, 08:00 and 16:00 h.

Isolation of cardiomyocytes. Left ventricular myocytes were enzymatically isolated from 39 male mice as previously described (16). The solutions were supplements of modified commercial minimal essential medium (MEM) Eagle-Joklik. The washing solution contained HEPES-MEM with the addition of $0.5 \mathrm{mM}$ EGTA. The resuspension medium contained HEPES-MEM supplemented with $0.5 \%$ BSA and $0.3 \mathrm{mM}$ $\mathrm{CaCl}_{2}$. Briefly, the hearts were quickly removed and connected to a plastic cannula for retrograde perfusion through the aorta. The cell isolation procedure consisted of 3 main steps: i) for low-calcium perfusion, blood washout in the presence of EGTA was performed for about $10 \mathrm{~min}$, and collagenase (selected type I, Worthington Biochemical Corp.) perfusion of the myocardium was carried out at $37^{\circ} \mathrm{C}$ with HEPES-MEM gassed with $85 \% \mathrm{O}_{2}, 15 \% \mathrm{~N}_{2}$, ii) the heart was removed from the cannula, the left ventricle was cut into small pieces and subsequently shaken in resuspension medium at $37^{\circ} \mathrm{C}$. Supernatant cell suspensions were washed and resuspended in resuspension medium, and iii) intact cells were enriched by centrifugation. This procedure was repeated 4-5 times.

Preparation of homogenates. Freshly isolated cardiomyocytes $\left(5 \times 10^{6}\right)$ were mixed with $1 \mathrm{ml}$ of cell lysis solution, repeatedly pipetted and sonicated in ice. In order to eliminate debris, the crude homogenate was centrifuged at $10,000 \mathrm{rpm}$ for $10 \mathrm{~min}$ at $4^{\circ} \mathrm{C}$. The supernatant was then used for the assay of SOD, GSH-Px and MDA.

Assay of antioxidant enzyme activity. The activities of SOD and GSH-Px enzyme were determined using assay kits (Jian Cheng Biology Research Center, China). SOD activity was measured through the inhibition of nitroblue tetrazolium (NBT) reduction by $\mathrm{O}^{2-}$ generated by the xanthine/xanthine oxidase system. One unit of SOD activity was defined as the amount of enzyme causing 50\% inhibition in $1 \mathrm{ml}$ reaction solution. GSH-Px activity was measured by using $\mathrm{H}_{2} \mathrm{O}_{2}$ and GSH as substrates. One unit of GSH-Px activity was defined as the amount of enzyme required to degrade $1 \mathrm{mM}$ of GSH per min subtracting non-enzymatic reaction. Each end-point assay was monitored by absorbance at $550 \mathrm{~nm}$ in SOD activity and at $412 \mathrm{~nm}$ in GSH-Px activity. Activity was expressed as U/ml.

MDA assay. MDA levels were determined by the thiobarbituric acid reactive substances (TBARS) assay using a MDA Assay kit (Jian Cheng Biology Research Center). TBARS is widely used to quantify the lipid peroxidation caused by high ROS levels. The concentration of TBARS was measured as a product of lipid peroxidation (17). Each end-point assay was monitored using absorbance at $532 \mathrm{~nm}$ and the results were expressed as $\mathrm{nmol} / \mathrm{ml}$.

mtDNA mutation assay. As previously described $(18,19)$, a nested PCR method was used to determine mtDNA deletion mutations in experimental DNA samples extracted from isolated cardiomyocytes. 


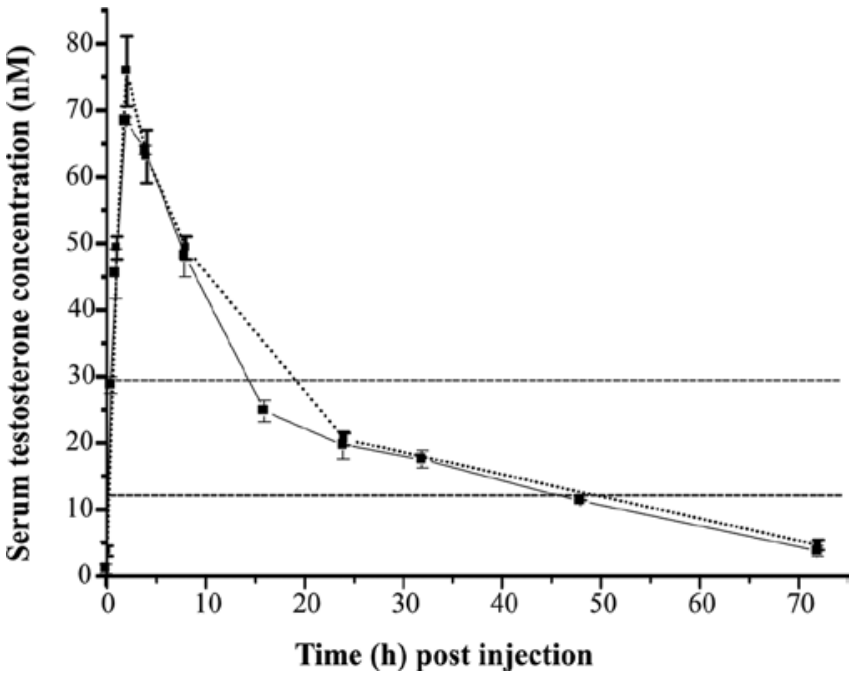

Figure 1. Serum concentration of total testosterone in castrated littermates after a single (solid line) and double (dashed line) $72 \mathrm{~h}$ intramuscular injection of testosterone propionate. The area between the dashed parallel lines denotes the physiological range of testosterone (12.6-28.7 nM).

The primer sequences were as follows: F1, taattcaagcctacg tattc (8549-8569); F2, gggatgtttttaggcttagg (13364-13383); F3, caagtccatgaccattaactgg (8644-8665); F4, gattttatgggtgtaatgcg (13338-13357); and F5, catgatctaggaggctgctgacctc (8934-8958) (19). Nested PCR conditions were initial denaturation at $94^{\circ} \mathrm{C}$ for $5 \mathrm{~min}$, followed by 30 cycles of denaturation, annealing and extension at $94^{\circ} \mathrm{C}$ for $30 \mathrm{sec}, 49^{\circ} \mathrm{C}$ for $30 \mathrm{sec}$ and $72^{\circ} \mathrm{C}$ for $90 \mathrm{sec}$, and a final extension at $72^{\circ} \mathrm{C}$ for $10 \mathrm{~min}$. Primers $\mathrm{F} 1$ and F2 were used as outer primers for the first 30 cycles, then $2 \mu \mathrm{l}$ of products of the first reaction were used with inner primers F3 and F4 for the second 30 cycles. Primers F2 and F5 were used to determine the relative quantification of wild-type mtDNA without deletions in each sample. The PCR condition consisted of $5 \mathrm{~min}$ at $95^{\circ} \mathrm{C}$, followed by 30 cycles of $45 \mathrm{sec}$ at $95^{\circ} \mathrm{C}, 45 \mathrm{sec}$ at $49^{\circ} \mathrm{C}$ and $5 \mathrm{~min}$ at $72^{\circ} \mathrm{C}$, and a final extension at $72^{\circ} \mathrm{C}$ for $10 \mathrm{~min}$. Amplified products were electrophoresed through $1.5 \%$ agarose gels and stained with ethidium bromide. The wild-type and deleted mtDNA could be detected with this method in one system. The gel was visualized on a transilluminator and photographed with a camera. M represented the sum of integrated optical density (IOD) values of deleted bands. $\mathrm{W}$ represented the IOD values of undeleted bands serving as the internal control. The proportion of mtDNA deletion mutations $=\mathrm{M} /(\mathrm{M}+\mathrm{W})(20)$. Products were purified and sequenced (Invitrogen Biotechnology Co.).

Statistical analysis. SPSS Version 13.0 (Statistical Software for Social Sciences, Chicago, IL) was used for statistical analysis. Results were expressed as the means \pm SD. Data were subsequently analyzed by one-way ANOVA, assumed with LSD and Dunnett's T3 multiple comparisons. A value of $\mathrm{P}<0.05$ was considered statistically significant.

\section{Results}

Determination of a dosing regimen to physiological testosterone levels in castrated mice. The normal range
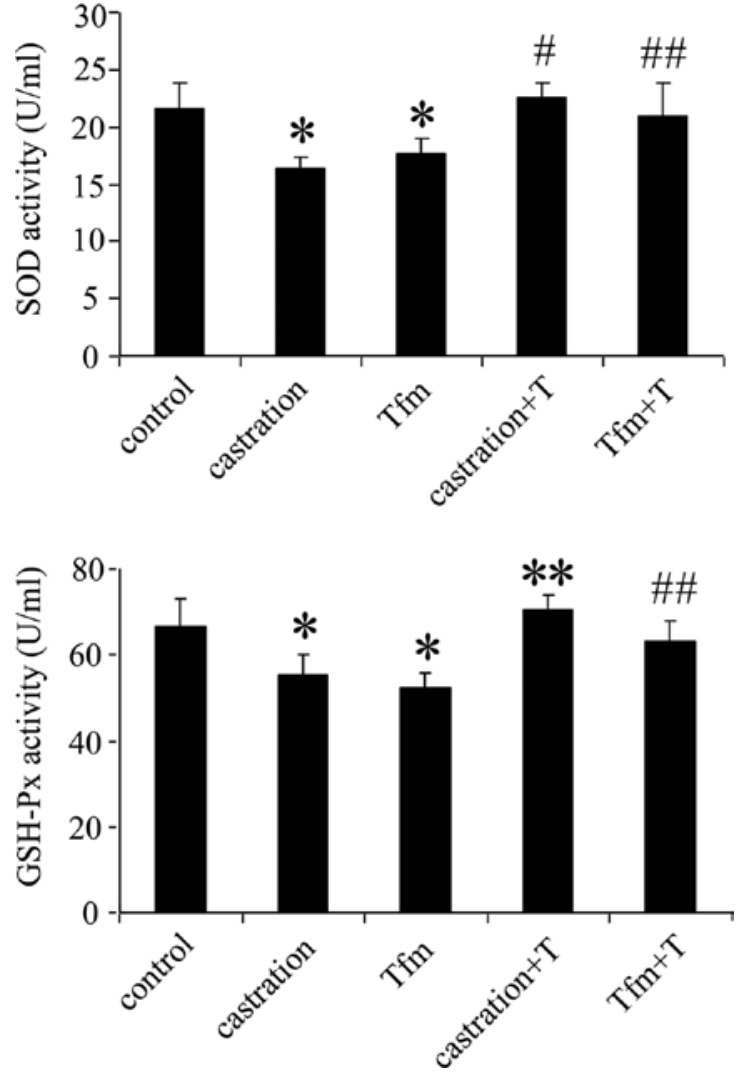

Figure 2. SOD and GSH-Px activities in cardiomyocytes. The values represent the means $\pm \mathrm{SD}$. ${ }^{*} \mathrm{P}<0.05$ vs. control; ${ }^{*} \mathrm{P}<0.001$ vs. castrated group; ${ }^{* *} \mathrm{P}<0.01$ vs. castrated group; ${ }^{\# \#} \mathrm{P}<0.05$ vs. Tfm group. T, testosterone.

of testosterone concentrations was from 12.6 to $28.7 \mathrm{nM}$. Baseline levels of serum testosterone after castration were about $6 \%$ of normal levels. The levels rose significantly from baseline after the $3 \mathrm{mg} / \mathrm{kg}$ intramuscular testosterone injection at $30 \mathrm{~min}$, reached a peak at $2 \mathrm{~h}$, and remained at the normal range between 14 and $50 \mathrm{~h}$ (Fig. 1). The mean area under the curve (AUC) for the $72 \mathrm{~h}$ period was $20.6 \mathrm{nM}$. A similar window of activity was observed after the second $72 \mathrm{~h}$ injection. The mean AUC for the second $72 \mathrm{~h}$ period was $22.7 \mathrm{nM}$. Pharmacokinetics showed that there was no statistical difference for testosterone concentrations between single and double administrations. Furthermore, after both administrations, the mean AUC was within the normal range. These results are in agreement with the study of Nettleship et al (21) and indicate a good reproducibility of the pharmacokinetic profile and a sufficient physiological replacement therapy of $3 \mathrm{mg} / \mathrm{kg} / 72 \mathrm{~h}$ intramuscular injection of testosterone propionate in castrated male mice.

Effect of testosterone on antioxidant enzyme activity in murine cardiomyocytes. As shown in Fig. 2, a significant decrease of the SOD and GSH-Px specific activities was observed in cardiomyocytes isolated from castrated and sham-operated Tfm mice compared to the age-matched control group $(\mathrm{P}<0.05)$. No significant differences were observed between the two experimental groups (castrated mice vs. shamoperated Tfm mice, $\mathrm{P}>0.05$ ). Testosterone treatment increased 


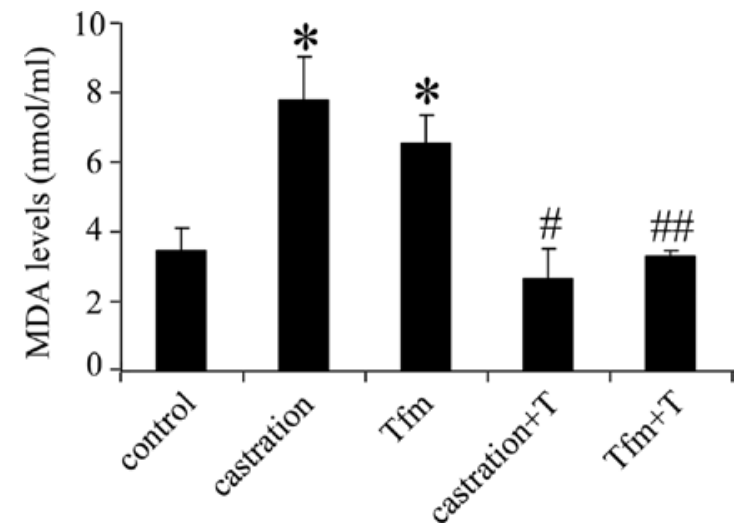

Figure 3. MDA levels in cardiomyocytes. The values represent the means \pm SD ${ }^{*} \mathrm{P}<0.01$ vs. control; ${ }^{\#} \mathrm{P}<0.001$ vs. castrated group; ${ }^{\# \#} \mathrm{P}<0.01$ vs. Tfm group. $\mathrm{T}$, testosterone.

SOD and GSH-Px activities in castrated and sham-operated Tfm mice compared to untreated mice $(\mathrm{P}<0.05)$. Furthermore, these levels were similar in testosterone-treated castrated and sham-operated Tfm mice $(\mathrm{P}>0.05)$.

Effect of testosterone on MDA levels in murine cardiomyocytes. Additionally, a significant increase in the MDA levels was found in cardiomyocytes isolated from castrated mice and sham-operated Tfm mice compared to the age-matched control group $(\mathrm{P}<0.01)$. No significant differences were observed between the two experimental groups (castrated mice vs. sham-operated Tfm mice, $\mathrm{P}>0.05$ ). Testosterone treatment resulted in a similar decrease in MDA levels in both castrated and sham-operated Tfm mice (Fig. 3), compared to untreated mice $(\mathrm{P}<0.01)$.

Effect of testosterone on the proportion of mtDNA deletion mutations in murine cardiomyocytes. PCR products of length 989-, 846-, 476- and 303-bp were directly sequenced. The product size, deletion size, junction sites and repeat length of these four observed deletions are presented in Table I. These common amplification products occured between directly repeated sequences in the mtDNA.

A product of $4549 \mathrm{bp}$ in length was detected in all groups using standard PCR conditions, representing amplification of wild-type mtDNA without deletions. An increased proportion of mtDNA deletion mutations was observed in castrated and sham-operated Tfm mice and these values were statistically similar $(0.49 \pm 0.02$ vs. $0.52 \pm .04 ; \mathrm{P}>0.05)$. The levels were significantly higher than those observed in the control mice $(0.26 \pm 0.05$; both $\mathrm{P}<0.001)$. After testosterone treatment, a decrease in mtDNA deletions was found in both castrated and sham-operated Tfm mice compared to the untreated mice $(0.38 \pm 0.02$ vs. $0.49 \pm 0.02$ and $0.35 \pm 0.06$ vs. $0.52 \pm 0.04$, respectively; both $\mathrm{P}<0.01)$. Moreover, these values were similar in testosterone-treated castrated and sham-operated Tfm mice $(0.38 \pm 0.02$ vs. $0.35 \pm 0.06 ; \mathrm{P}>0.05)$ (Fig. 4).

Table I. Structure of mouse mtDNA deletions.

\begin{tabular}{|c|c|c|c|c|}
\hline Deletion size (bp) & Breakpoints & Direct repeat (bp) & Repeated sequences & Product size (bp) \\
\hline 3726 & $9553 / 13279$ & 14 & AAGCAAATCCATAT & 989 \\
\hline 3867 & $9089 / 12956$ & 15 & AGCССТАСТААТTAC & 846 \\
\hline 4236 & $8884 / 13120$ & 13 & TCTTTGCAGGATT & 476 \\
\hline 4414 & $8758 / 13172$ & 11 & TCCTCACAATA & 303 \\
\hline
\end{tabular}

mtDNA, mitochondrial DNA.

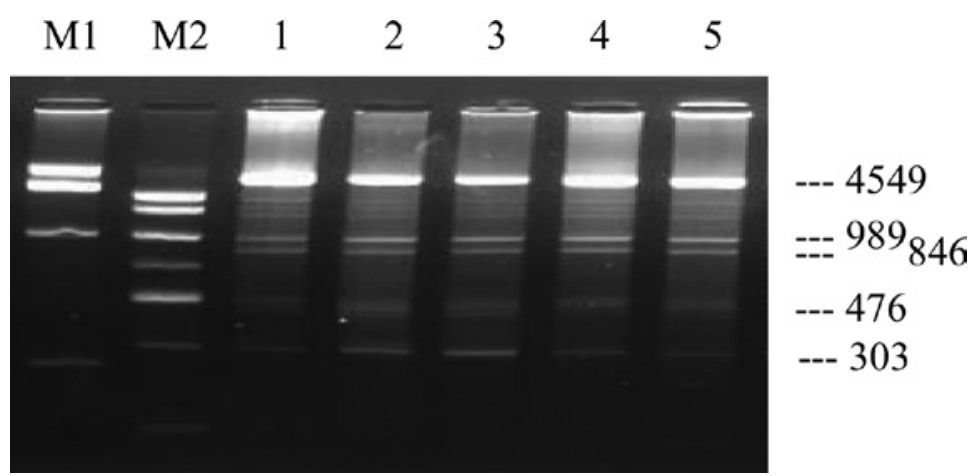

Figure 4. Detection of multiple mtDNA deletions in cardiomyocytes. Line 1, control group; Line 2, castrated group; Line 3, Tfm group; Line 4, castrated + testosterone group; Line 5, Tfm + testosterone group. Numbers on the right side of the image indicate the size of the expected product. M1 marker, fragments of size 5000, 2500, 1000 and $250 \mathrm{bp}$ are visible in order from the top of the lane; M2 marker, fragments of size 2000, 1500, $1000,700,500,300$ and 100 bp. 


\section{Discussion}

We found that testosterone concentrations in castrated mice were $94 \%$ lower than in control mice. Testosterone concentrations in sham-operated Tfm mice were $89 \%$ (data not shown), a result also reported by Jones et al (15). Testosterone therapy restored physiological testosterone levels in castrated and Tfm mice, and finally, oxidative damage that occurred in cardiomyocytes after testosterone deficiency and testosterone therapy was observed.

Antioxidant defenses, both enzymatic and non-enzymatic, protect the cell from ROS that can cause oxidative damage (22). The cellular antioxidant defense system consists of SOD, GSH-Px and other related enzymes (23). This dynamic system must be precisely regulated in order to protect cells from oxidative damage. The present study revealed that left ventricular myocytes from castrated and sham-operated Tfm mice had a decrease in SOD and GSH-Px enzyme activities compared to the control mice. Moreover, the parameter was statistically similar in these two groups. These observations provide evidence that testosterone deficiency contributes to the deterioration of antioxidant defense mechanisms in cardiomyocytes. In this respect, the results of our study are consistent with those reported by Barp et al (24) and Kłapcińska et al (25) in hearts and Meydan et al (23) in the hippocampal tissue. Data regarding the potential antioxidant role of exogenous testosterone in the heart are very scarce, and conflicting results have been observed in different tissues. Kłapcińska et al (25) reported that testosterone replacement in castrated rats exacerbated the decline in cardiac muscle antioxidant defense, including SOD and GSH-Px activities. In the hippocampus, exogenous testosterone increased SOD and GSH-Px enzyme activities which were reduced after castration (23). Marin et al (3) found that the activities of total SOD and GSH-Px were unaffected in neutrophils after testosterone treatment. In the present investigation, long-term physiological testosterone therapy significantly increased SOD and GSH-Px activities, suggesting an improvement of antioxidant activity. The discrepancies between our results and the results of others may be attributed to the fact that those experiments were performed using tissue lysates, in which case other cell types are present and could mask changes occurring in ventricular cardiomyocytes. The importance of this is paramount as non-cardiac cells account for about twice the number of ventricular cells compared to cardiomyocytes. Furthermore, after comparing our results to those found in other tissues, we suggest that the effect of testosterone is tissue-dependent (12).

Membrane lipids, which are rich in polyunsaturated fatty acids, are vulnerable to peroxidation by oxidants. The level of MDA, which occurs due to lipid peroxidation, is an indicator of oxidative damage. Lipid peroxidation has been shown to increase in cardiac mitochondria during oxidative damage $(26,27)$. We observed that cardiomyocyte MDA levels significantly increased in castrated and sham-operated Tfm mice compared to control mice. This increase demonstrates that oxidative damage occurrs in cardiomyocytes as a result of lipid peroxidation attributed to testosterone deficiency. In agreement with our findings, castration leads to higher MDA content (25) and an increase in lipid peroxidation (28) in the left ventricle. Androgens have been shown to effectively prevent the formation of lipid peroxidation (29). It has been reported that testosterone administration leads to a decrease in MDA levels in rat liver (30) and brain $(23,31)$. In the study by Sreelatha Kumari et al, administration of testosterone in castrated rats partially reversed the increase in lipid peroxidation in the hearts (28). However, Kłapcińska et al (25) found that testosterone replacement in castrated male rats led to a further increase in MDA levels in the left ventricle. The reason for this discrepancy is unclear. Our study indicates that testosterone therapy causes a decrease in the MDA levels in cardiomyocytes, which are increased by testosterone deficiency.

mtDNA is especially susceptible to oxidative damage due to its proximity to the inner mitochondrial membrane where oxidants are generated, and to the lack of protective histones and DNA repair activity (32). DNA damage in postmitotic tissues, including the heart, is more extensive than that observed in mitotic tissues, such as the liver, since cardiomyocytes have limited ability to undergo mitosis (33). Oxidative damage has been proposed to involve single- or double-stranded DNA breaks, leading to mtDNA deletions. mtDNA deletions are flanked by exact and inexact direct repeats. Three mutant mtDNAs with 3726-, 3867- and 4236-bp deletions are most often observed in the aging murine heart, brain, kidney, liver and cardiomyocytes (18-20,34). In the study by Wang et al, the 4056 bp deletion was often found in aged tissues and was associated with directly repeated sequences in the mtDNA (19). Similaly, the deletion sizes of 3726-, 3867- and 4236-bp in length were amplified in both controlled and experimental cardiomyocytes in our study. Another deletion observed in mtDNA was $4414 \mathrm{bp}$, which was associated with $11 \mathrm{bp}$ direct repeats, supporting the view that large-scale deletions most frequently occur at direct repeat sequences $(18,19,34)$. Although we were unable to determine the concentration of the mtDNA genome, the wide-type internal control allowed for a comparison of the relative quantitation of deleted mtDNA molecules. Testosterone deficiency, described by castration and $\mathrm{Tfm}$, resulted in higher proportions of mtDNA deletions compared to normal testosterone levels, while testosterone administration partially reversed these increases. In our experiment, we estimated that multiple deletion products were amplified in all experimental groups due to a higher DNA input (500 ng) (19) or the effect of isolation procedure. There are few studies on mtDNA deletion mutations induced by testosterone. It is possible that testosterone stimulates the alternation of ROS production, thereby dramatically changing the amount of mutations in mtDNA.

As previously mentioned, we observed a protective role of testosterone therapy against oxidative stress. The amelioration was statistically similar in castrated and sham-operated Tfm mice after testosterone therapy. Due to the following observations we conclude that the positive effects of testosterone on oxidative stress occur via an AR-independent pathway: i) Tfm mice carry non-functional $\mathrm{AR}$ and still respond to testosterone, and ii) castrated mice with functional AR show signs of oxidative stress that can be cured with testosterone. Research concerning the effects of testosterone on the production of ROS in the heart does not explain the mechanism behind the observed results $(25,28)$. Ahlbom et al (13) and Lin et al (35) found that oxidative stress modulated by testos- 
terone in cerebellar granule cells and prostate cancer cells was mediated via an AR mediated mechanism. It is difficult to say why we could not replicate the previously obtained results. As mentioned above, testosterone has a tissue-dependent effect, and we presume that its antioxidant properties may be tissue-dependent and involve different signaling pathways in cardiomyocytes. We hypothesize that aromatization to $17 \beta$-estradiol could occur and that the effects of testosterone treatment could then be mediated through different receptors.

In conclusion, our results support the idea that testosterone deficiency contributes to oxidant stress in Tfm and castrated male mice cardiomyocytes. This study has demonstrated a beneficial effect of physiological testosterone on oxidant stress, an action that is independent of the typical AR. Reduced concentrations of testosterone in the elderly and in some pathological conditions may contribute to the development of heart disease through the induction of oxidative stress. The maintenance of physiological testosterone concentrations may maintain the redox balance in murine cardiomyocytes.

\section{Acknowledgements}

This study was supported by the National Key Fundamental Research and Development Project (No. 2007CB507404).

\section{References}

1. Marsh JD, Lehmann MH, Ritchie RH, Gwathmey JK, Green GE and Schiebinger RJ: Androgen receptor mediate hypertrophy in cardiac myocytes. Circulation 98: 256-261, 1998.

2. Golden KL, Marsh JD, Jiang Y and Moulden J: Gonadectomy alters myosin heavy chain composition in isolated cardiac myocytes. Endocrine 24: 137-140, 2004.

3. Marin DP, Bolin AP, Dos Santos Rde C, Curi R and Otton R: Testosterone suppresses oxidative stress in human neutrophils. Cell Biochem Funct 28: 394-402, 2010.

4. Malkin CJ, Pugh PJ, West JN, van Beek EJ, Jones TH and Channer KS: Testosterone therapy in men with moderate severity heart failure: a double-blind randomized placebo controlled trial Eur Heart J 27: 57-64, 2006.

5. Li ZB, Wang J, Wang JX, Chen XM and Jiang SS: Testosterone therapy improves cardiac function of male rats with right hear failure. Zhanghua Nan Ke Xue 15: 994-1000, 2009.

6. Singal PK, Khaper N, Palace V and Kumar D: The role of oxidative stress in the genesis of heart disease. Cardiovasc Res 40: 426-432, 1998

7. Bernhard D and Laufer G: The aging cardiomyocyte: a minireview. Gerontology 54: 24-31, 2008.

8. Ma YS, Wu SB, Lee WY, Cheng JS and Wei YH: Response to the increase of oxidative stress and mutation of mitochondrial DNA in aging. Biochim Biophys Acta 1790: 1021-1029, 2009.

9. Wei YH: Mitochondrial DNA alterations as ageing-associated molecular events. Mutat Res 275: 145-155, 1992.

10. Richter C: Oxidative damage to mitochondrial DNA and its relationship to ageing. Int J Biochem Cell Biol 27: 647-653, 1995.

11. Békési G, Kakucs R, Várbíró S, Rácz K, Sprintz D, Fehér J and Székács B: In vitro effects of different steroid hormones on superoxide anion production of human neutrophil granulocytes. Steroids 65: 889-894, 2000.

12. Alonso-Alvarez C, Bertrand S, Faivre B, Chastel O and Sorci G: Testosterone and oxidative stress: the oxidation handicap hypothesis. Proc Biol Sci 274: 819-825, 2007.

13. Ahlbom E, Prins GS and Ceccatelli S: Testosterone protects cerebellar granule cells from oxidative stress-induced cell death through a receptor mediated mechanism. Brain Res 892: $255-262,2001$
14. He WW, Kumar MV and Tindall DJ: A frame-shift mutation in the androgen receptor gene causes complete androgen insensitivity in the testicularfeminized mouse. Nucleic Acids Res 19: 2373-2378, 1991

15. Jones RD, Pugh PJ, Hall J, Channer KS and Jones TH: Altered circulating hormone levels, endothelial function and vascular reactivity in the testicular feminised mouse. Eur J Endocrinol 148: 111-120, 2003.

16. Leri A, Liu Y, Wang X, Kajstura J, Malhotra A, Meggs LG and Anversa P: Overexpression of insulin-like growth factor-1 attenuates the myocyte renin- angiotensin system in transgenic mice. Circ Res 84: 752-762, 1999.

17. Yagi K: Assay for blood plasma or serum. Methods Enzymol 105: 328-331, 1984.

18. Brossas JY, Barreau E, Courtois Y and Tréton J: Multiple deletions in mitochondrial DNA are present in senescent mouse brain. Biochem Biophys Res Commun 202: 654-659, 1994.

19. Wang E, Wong A and Cortopassi G: The rate of mitochondrial mutagenesis is faster in mice than humans. Mutat Res 377: 157-166, 1997.

20. Zeng Z, Zhang Z, Yu H, Corbley MJ, Tang Z and Tong T: Mitochondrial DNA deletions are associated with ischemia and aging in Balb/c mouse brain. J Cell Biochem 73: 545-553, 1999.

21. Nettleship JE, Jones TH, Channer KS and Jones RD: Physiological testosterone replacement therapy attenuates fatty streak and improves high-density lipoprotein cholesterol in the Tfm mouse: an effect that is independent of the classic androgen receptor. Circulation 116: 2427-2434, 2007.

22. Park CJ, Park SA, Yoon TG, Lee SJ, Yum KW and Kim HJ: Bupivacaine induces apoptosis via ROS in the Schwann cell line. J Dent Res 84: 852-857, 2005.

23. Meydan S, Kus I, Tas U, et al: Effects of testosterone on orchiectomy-induced oxidative damage in the rat hippocampus. J Chem Neuroanat 40: 281-285, 2010.

24. Barp J, Araújo ASR, Rigatto KV, Llesuy S, Belló-Klein A and Singal P: Myocardial antioxidant and oxidative stress changes due to sex hormones. Braz J Med Biol Res 35: 1075-1081, 2002.

25. Kłapcińska B, Jagsz S, Sadowska-Krepa E, Górski J, Kempa K and Langfort J: Effects of castration and testosterone replacement on the antioxidant defense system in rat left ventricle. J Physiol Sci 58: 173-177, 2008.

26. Ji LL, Dillon D and Wu E: Myocardial aging: antioxidant enzyme systems and related biochemical properties. Am J Physiol 261: R386-R392, 1991.

27. Judge S, Jang YM, Smith A, Hagen T and Leeuwenburgh C: Age-associated increases in oxidative stress and antioxidant enzyme activities in cardiac interfibrillar mitochondria: implications for the mitochondrial theory of aging. FASEB J 19: 419-421, 2005

28. Sreelatha Kumari KT, Menon VP and Leelamma S: Testosterone and lipid peroxide metabolism in orchidectomised rats. Indian $\mathrm{J}$ Exp Biol 31: 323-326, 1993.

29. Bilińska B, Wiszniewska B, Kosiniak-Kamysz K, et al: Hormonal status of male reproductive system: androgens and estrogens in the testis and epididymis. In vivo and in vitro approaches. Reprod Biol 6 (Suppl 1): S43-S58, 2006.

30. Huh K, Shin US, Choi JW and Lee SI: Effect of sex hormones on lipid peroxidation in rat liver. Arch Pharm Res 17: 109-114, 1994.

31. Guzman DC, Mejia GB, Vazquez IE, Garcia EH, Del Angel DS and Olguín HJ: Effect of testosterone and steroids homologues on indolamines and lipid peroxidation in rat brain. J Steroid Biochem Mol Biol 94: 369-373, 2005.

32. Shigenaga MK, Hagen TM and Ames BN: Oxidative damage and mitochondrial decay in aging. Proc Natl Acad Sci USA 91: 10771-10778, 1994.

33. Izzotti A, Cartiglia C, Taningher M, De Flora S and Balansky R: Age-related increases of 8-hydroxy-2'-deoxyguanosine and DNAprotein crosslinks in mouse organs. Mutat Res 446: 215-223, 1999.

34. Tanhauser SM and Laipis PJ: Multiple deletions are detectable in mitochondrial DNA of aging mice. J Biol Chem 270: 24769-24775, 1995.

35. Lin H, Lu JP, Laflamme P, et al: Inter-related in vitro effects of androgens, fatty acids and oxidative stress in prostate cancer: a mechanistic model supporting prevention strategies. Int J Oncol 37: 761-766, 2010. 